\title{
Tinjauan Literatur Kepemimpinan Transformasional pada Usaha Kecil Menengah (UKM)
}

\author{
Authors: \\ Muhammad Lutfi Lazuardi ${ }^{1}$ \\ Muhammad Rizal ${ }^{2}$ \\ Ria Arifianti ${ }^{3}$ \\ Affiliations: \\ ${ }^{1,2,3}$ Administrasi Bisnis, \\ Fakultas Ilmu Sosial dan Ilmu \\ Politik, Universitas \\ Padjadjaran, Indonesia \\ Corresponding Author: \\ Muhammad Lutfi Lazuardi ${ }^{1}$ \\ Emails: \\ 1'muhammad@mail.unpad.ac.id \\ ²m.rizal@unpad.ac.id \\ 3r.arifianti@unpad.ac.id
}

Article History:

Received: September 20, 2018

Revised : November 29, 2018

Accepted: December 08, 2018

How to cite this article:

Lazuardi, M. L., Rizal, M., \&

Arifianti, R. (2018). Tinjauan

Literatur Kepemimpinan

Transformasional pada Usaha

Kecil Menengah (UMKM).

Organum: Jurnal Saintifik

Manajemen dan Akuntansi,

1(2), 88-98. doi:

https://doi.org/10.35138/organu

m.v1i2.37

Journal Homepage:

ejournal.winayamukti.ac.id/ind

ex.php/Organum

\section{Copyright:}

(C) 2018. Published by Organum: Jurnal Saintifik

Manajemen dan Akuntansi.

Faculty of Economics and

Business. Winaya Mukti

University.
Abstract. Transformational leadership is a leadership style. The leader, capable of identifying the changes that need to be made, creating a vision to guide the changes through inspiration and implementing them under group commitment. The role of a leader in exerting his/her influences is so important for supporting the company activities, including Small and Medium Enterprises (SMEs). A comprehensive understanding of the state-of-the-art of transformational leadership is still needed. This article aims to classify, identify scientific publications and carry out a thematic analysis of the latest literature to create an extensive and detailed understanding of transformational leadership specifically in Small and Medium Enterprises (SMEs). The research method was conducted by using Systematic Mapping Study (SMS) to analyze scientific publications of transformational leadership in Small and Medium Enterprises (SMEs) which were generated based on the focus and type of research from time to time. The results of this study produced a categorization and quantification of transformational leadership studies in various dimensions as well as an overview of topics and trends in transformational leadership research in Small and Medium Enterprises (SMEs) today.

Keywords: Transformational leadership; small and medium enterprises; systematic mapping study.

Abstrak. Kepemimpinan transformasional adalah gaya kepemimpinan yang pemimpinnya mampu mengidentifikasi perubahan yang dibutuhkan, menciptakan visi untuk memandu perubahan melalui inspirasi, dan menjalankan perubahan dengan komitmen anggota kelompok. Peran pemimpin perusahaan sangat diperlukan apabila mampu memberikan pengaruh dalam menunjang aktivitas perusahaan. Termasuk pada perusahaan skala Usaha Kecil Menengah (UKM). Pemahaman menyeluruh tentang state-of-the-art dari kepemimpinan transformasional masih dibutuhkan. Oleh karena itu, artikel ini bertujuan untuk mengklasifikasikan, mengidentifikasi publikasi-publikasi ilmiah dan melakukan analisis tematik terhadap literatur terkini guna menciptakan pemahaman yang ekstensif dan terperinci di bidang kepemimpinan transformasional secara spesifik pada Usaha Kecil Menengah (UKM). Metode penelitian dilakukan dengan cara Systematic Mapping Study (SMS) untuk menelaah publikasi ilmiah di bidang kepemimpinan transformasional pada Usaha Kecil Menengah (UKM) yang dihasilkan berdasarkan fokus dan tipe riset dari waktu ke waktu. Hasil penelitian ini menghasilkan kategorisasi dan kuantifikasi studi kepemimpinan transformasional dalam berbagai dimensi, serta ikhtisar topik dan tren penelitian kepemimpinan transformasional pada Usaha Kecil Menengah (UKM) saat ini.

Kata Kunci: Kepemimpinan transformasional; usaha mikro kecil dan menengah; studi pemetaan sistematis. 


\section{Pendahuluan}

$\mathrm{F}$ lenomena mengenai kepemimpinan transformasional merupakan isu menarik yang perlu diteliti (Hermawati, Suhermin, \& Puji, 2019). Penelitian mengenai kepemimpinan transformasional ini bisa menjadi implikasi praktis bagi perusahaan. Peran pemimpin dalam perusahaan diharapkan mampu memberikan pengaruh positif dan sangat diperlukan dalam menunjang aktivitas serta fleksibilitas perusahaan. Termasuk pada perusahaan skala kecil menengah (UKM). UKM memiliki kemampuan bertahan yang lebih baik karena lebih fleksibel dan sederhana. Kejadian moneter pada tahun 1998 bisa menjadi bukti meski krisis ekonomi melanda banyak dari UKM masih bisa bertahan dibanding usaha-usaha besar yang terikat dengan permodalan bank yang saat itu terkena imbas krisis ekonomi. Ini semua menjadi hal menarik untuk dibahas. Oleh karena itu, perlu adanya penelitian untuk mengetahui perkembangan penelitian mengenai kepemimpinan transformasional pada UKM untuk mendapatkan pengetahuan yang lebih luas.

Untuk memahami perspektif penelitian yang telah ada, peneliti melakukan studi sistematis (Systematic Mapping Study). Studi ini merupakan tinjauan literatur dengan memetakan penelitian-penelitian yang sudah ada terkait kepemimpinan transformasional pada Usaha Kecil Menengah (UMKM) dari Database Electronic International, yaitu Emerald Insight \& Scopus.

Tujuan dari studi pemetaan sistematis (Systematic Mapping Study) ini adalah untuk membentuk latar belakang riset lebih lanjut serta menggali wawasan yang lebih dalam tentang kajian kepemimpinan transformasional dan bagi akademisi untuk mengidentifikasi kesenjangan penelitian (gaps) di masa yang akan datang. Studi SMS merupakan metode yang tepat sebagai pendekatan studi literatur karena didukung dengan
7548 artikel terkait kepemimpinan transformasional dari penelusuran di Scopus \& Emerald Insight Electronic Database. SMS diterapkan untuk menguraikan jenis aktivitas penelitian yang telah dilakukan dalam penelitian ini. SMS menjelaskan penelitian pada tingkat tinggi dan memetakan penelitian dari pada menyelidiki pertanyaan penelitian secara rinci (Petersen et al., 2008).

Untuk mencapai tujuan penelitian, dibutuhkan pertanyaan penelitian (Research Questions) lebih luas untuk menemukan temuan-temuan yang akurat dan relevan pada Database Electronic International Emerald Insight \& Scopus. Secara keseluruhan peneliti menganalisis hasil pencarian yang relevan dengan kajian kepemimpinan transformasional berdasarkan rumusan pertanyaan utama, yang meliputi, 1) RQ1: Berapa persentase penelitian kepemimpinan transformasional pada UKM, dari key string "Transformational Leadership" pada Database Journal Electronic International Scopus \& Emerald Insight?; 2) RQ2: Bagaimana tipe artikel dan metode penelitian yang digunakan?; dan 3) RQ3: Bagaimana perkembangan topik di setiap negara dan perkembangan pada rentang waktu 10 tahun terakhir?.

\section{Kajian Literatur}

Menurut Hasibuan (2011:157) pemimpin adalah seseorang yang mempergunakan wewenang dan kepemimpinannya untuk mengarahkan orang lain serta bertanggung jawab atas pekerjaan orang tersebut dalam mencapai suatu tujuan. Selain itu, Rivai (2012) mengatakan bahwa, seorang pemimpin dalam suatu organisasi harus memiliki kriteria tertentu layaknya seorang pemimpin yang sejati. Kriteria tersebut antara lain;

1) Pengaruh; seorang pemimpin adalah seorang yang memiliki orang-orang pendukung yang turut membesarkan nama sang pimpinan. Pengaruh itu 
menjadikan sang pemimpin diikuti dan membuat orang lain tunduk pada perintah yang dikatakan sang pemimpin.

2) Kekuasaan/power; seorang pemimpin umumnya diikuti oleh orang lain karena ia memiliki kekuasaan yang membuat orang lain menghargai keberadaannya. Tanpa kekuasaan atau kekuatan yang dimiliki sang pemimpin tentunya tidak ada orang yang mau menjadi pendukungnya. Kekuasaan dan kekuatan yang dimiliki seorang pemimpin ini menjadikan orang lain akan tergantung pada apa yang dimiliki seorang pemimpin, tanpa itu ia tidak akan bisa berbuat apa-apa. Hubungan ini menjadikan hubungan yang bersifat simbiosis mutualisme, dan kedua belah pihak merasa saling diuntungkan.

3) Wewenang; wewenang dapat diartikan sebagai hak yang diberikan kepada pemimpin untuk menetapkan sebuah keputusan dalam melaksanakan suatu hal/kebijakan. Wewenang juga dapat dialihkan kepada karyawan apabila pemimpin percaya bahwa karyawan tersebut mampu melaksanakan tugas dan tanggung jawab dengan baik, sehingga karyawan diberi kepercayaan untuk melaksanakan tanpa perlu campur tangan dari sang pemimpin.

4) Pengikut; seorang pemimpin yang memiliki pengaruh, kekuasaan/power, dan wewenang, tidak dapat dikatakan sebagai pemimpin apabila dia tidak memiliki pengikut yang berada di belakangnya yang dapat memberi dukungan untuk mengikuti apa yang dikatakan pemimpin.

Kepemimpinan transformasional memiliki pengertian yang bertujuan untuk perubahan. Sesuai dengan kepemimpinan secara alami yaitu adanya pergerakan untuk mencapai tujuan, maka tujuan yang dimaksud adalah perubahan. Perubahan ini diasumsikan sebagai perubahan ke arah yang lebih baik, menentang status quo dan aktif (Lensufiie, 2010). Serupa dengan pernyataan Lensufiie, kepemimpinan transformasional adalah kepemimpinan yang menciptakan perubahan positif dalam pengikut, dan mereka mengurus kepentingan satu sama lain, serta bertindak dalam kepentingan kelompok secara keseluruhan (Warrilow, 2012).

Menurut Bass (Yukl, 2010:313), kepemimpinan transformasional adalah suatu keadaan yang para pengikut dari seorang pemimpin transformasional merasa adanya kepercayaan, kekaguman, kesetiaan, dan hormat terhadap pemimpin tersebut, serta mereka termotivasi untuk melakukan lebih dari pada yang awalnya diharapkan mereka. Maka kepemimpinan transfromasional diharapkan mampu membawa dampak positif baik untuk perusahaan besar maupun skala Usaha Kecil Menengah (UKM).

Disisi lain menurut U.S Small Business Administration (SBA) Small Medium Enterprise atau UKM adalah "Usaha yang dimiliki dan dijalankan secara mandiri, didirikan untuk meraih keuntungan dan tidak dominan di bidangnya, serta menjual produk yang dihasilkan ke pelanggan di pasar lokal."

Masing-masing negara memiliki definisi yang berbeda mengenai UKM atau Small Medium Enterprise. Menurut UU No. 20 Tahun 2008, usaha jenis ini dibagi dalam dua pengertian, yakni:

1) Usaha Kecil, merupakan entitas usaha yang memiliki kekayaan bersih lebih dari lima puluh juta rupiah sampai dengan paling banyak lima ratus juta rupiah, tidak termasuk tanah dan bangunan tempat usaha, serta memiliki hasil penjualan tahunan lebih dari tiga ratus juta rupiah sampai dengan 
paling banyak dua miliar lima ratus juta rupiah.

2) Usaha

merupakan entitas usaha yang memiliki kekayaan bersih lebih dari lima ratus juta rupiah sampai dengan paling banyak sepuluh miliar rupiah, tidak termasuk tanah dan bangunan tempat usaha, serta memiliki hasil penjualan tahunan lebih dari dua miliar lima ratus juta rupiah sampai dengan paling banyak lima puluh miliar rupiah.

Peran pemimpin dalam perusahaan sangat diperlukan dalam memberikan pengaruh guna menunjang aktivitas perusahaan. Termasuk pada perusahaan skala kecil menengah (UKM). Maka penelitian ini diharapkan mampu memicu munculnya penelitian-penelitian lain di bidang kepemimpinan transformasional pada UKM.

\section{Metode Penelitian}

Penelitian ini menggunakan Systematic Mapping Study (SMS) yang diterapkan untuk menguraikan jenis aktivitas penelitian yang telah dilakukan. SMS menjelaskan penelitian pada tingkat tinggi dan memetakan penelitian dari pada menyelidiki pertanyaan penelitian secara rinci (Petersen et al., 2008). Dengan kata lain, SMS dapat dianggap sebagai metode untuk mendapatkan gambaran umum tentang area penelitian tertentu (Kitchenham \& Charters, 2007).

Proses pencarian dan analisis dibuat seakurat mungkin untuk menambah keakuratan studi SMS. Dengan demikian, pada bagian ini mencirikan proses pemilihan sumber data, strategi penerapan untuk membuat String pencarian, serta menentukan kriteria eksklusi dan inklusi.

Penelitian ini mengadopsi proses pencarian dari penelitian (Banaeianjahromi, $\mathrm{N} \&$ Smolander, 2016). Dalam proses ini, setiap langkah memiliki hasil dan peta sistematis (Systematic Mapping), yang merupakan hasil akhir dari proses pemetaan. Pada Gambar 1 kami mengilustrasikan proses SMS lengkap yang digunakan dalam penelitian ini, kami mengacu pada penelitian yang dilakukan dan sesuai instruksi oleh (Kitchenham \& Charters, 2007) dan Petersen et al. (2008).

Peneliti melakukan pencarian secara online pada Database Elektronik International Scopus \& Emerald Insight. Emerald Insight merupakan pangkalan data pustaka yang mengandung abstrak dan artikel jurnal akademik internasional bereputasi.

Gambar 1. Proses SMS (Pencarian)

\begin{tabular}{|c|c|c|}
\hline $\begin{array}{l}\text { Definisi dari } \\
\text { pertanyaan } \\
\text { penelitian }\end{array}$ & $\begin{array}{l}\text { Tinjauan ruang } \\
\text { lingkup }\end{array}$ & Seluruh Paper \\
\hline $\begin{array}{l}\text { Melakukan } \\
\text { pencarian di } \\
\text { Emerald Insight \& } \\
\text { Scopus dengan } \\
\text { String } \\
\text { "Transformational } \\
\text { Leadership" }\end{array}$ & Semua papers & 7548 \\
\hline $\begin{array}{l}\text { Mengfokuskan } \\
\text { pada kajian SMEs } \\
\text { dengan } \\
\text { menambahkan } \\
\text { String AND } \\
\text { "Small and }\end{array}$ & $\begin{array}{l}\text { Artikel dan scholary } \\
\text { jurnal }\end{array}$ & 211 \\
\hline
\end{tabular}




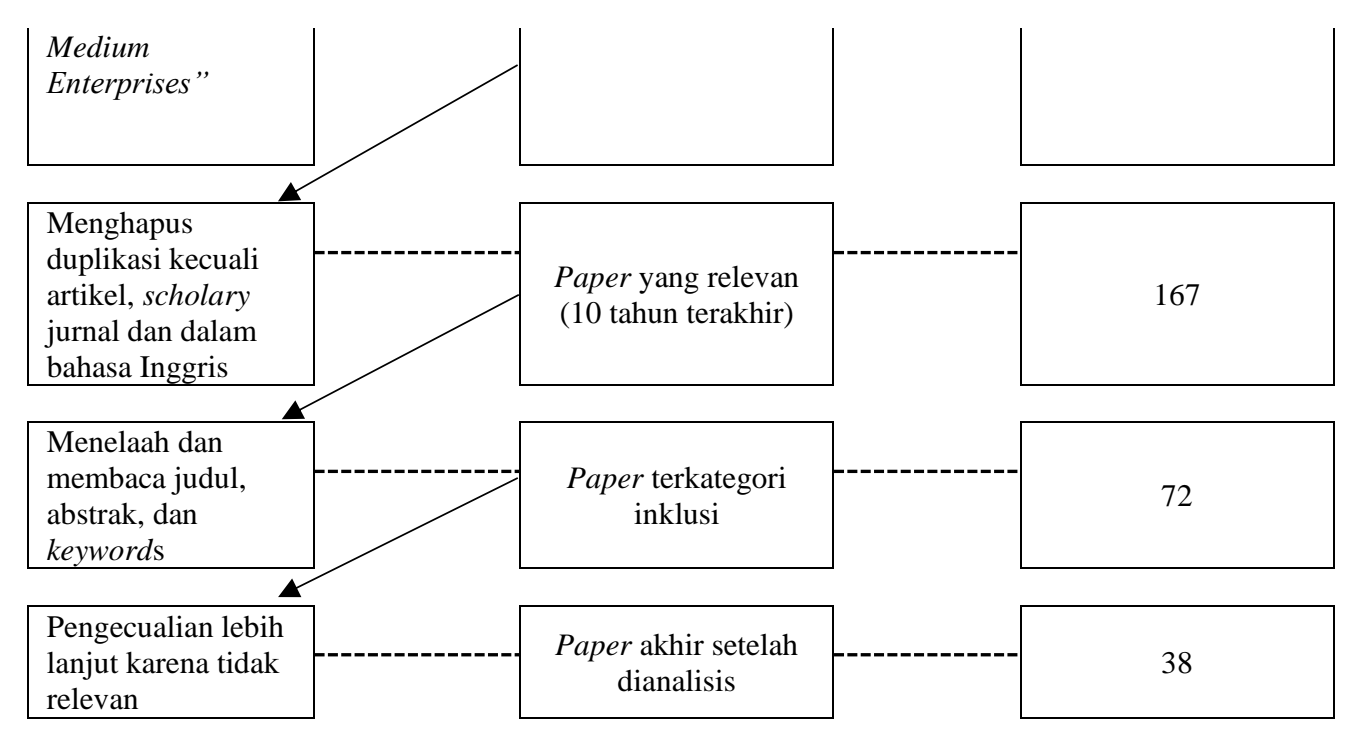

Sumber: (Banaeianjahromi, N \& Smolander, 2016)

Selanjutnya, langkah untuk menentukan kategori artikel pengecualian yang disebut kriteria eksklusi dan artikel inklusi merupakan salah satu kegiatan studi pemetaan untuk tidak mengikutsertakan artikel yang tidak relevan dan mencakup artikel yang relevan (Petersen et al., 2008). Pada penelitian ini, kami merumuskan kriteria eksklusi dan inklusi untuk mempermudah pemetaan Tabel 1 (Barbosa \& Alves, 2011; Banaeianjahromi, N \& Smolander, 2016).

\section{Tabel 1. Keriteria Inkusi dan Eksklusi}

\begin{tabular}{ll}
\hline Inklusi & Eksklusi \\
\hline $\begin{array}{l}\text { 1. Penelitian yang } \\
\text { berfokus pada }\end{array}$ & 1. Makalah yang tidak membahas tentang keunggulan \\
penelitian & 2. Bampetitif \\
$\begin{array}{l}\text { kepemimpinan } \\
\text { transformasional }\end{array}$ & $\begin{array}{l}\text { 3. Disertasi, tesis, bagian buku, deskripsi produk, presentasi, } \\
\text { laporan kerja, literatur perdagangan, catatan editorial, }\end{array}$ \\
2. Bahasa Inggris & \multicolumn{1}{l}{ literatur yang tidak jelas } \\
3. Hanya artikel dan & 4. Makalah yang belum melewati peer review \\
$\begin{array}{l}\text { scholary journals } \\
\text { 4. Makalah yang sudah } \\
\text { melewati peer review }\end{array}$ & 5. Penelitian duplikat \\
\hline
\end{tabular}

\section{Langkah Pengklasifikasian}

Pada proses pemetaan sistematis, untuk menganalisis dan mengklasifikasikan artikel yang sudah diseleksi berdasarkan kriteria, peneliti merumuskan tiga aspek untuk pengklasifikasian artikel yang ditemukan yang telah relevan. Pada kategori pertama kami mengelompokkan artikel berdasarkan fokus penelitian (research focus) dengan acuan (Petersen et al., 2008). Kategori kedua mendefinisikan tipe artikel (paper type) berdasarkan klasifikasi yang disajikan dalam (Wieringa, Maiden, Mead, \& Rolland, 2006). 
Tabel 2. Kategori Klasifikasi

\begin{tabular}{ll}
\hline \multicolumn{1}{c}{ Paper Type } & \multicolumn{1}{c}{ Penjelasan } \\
\hline Validation Research & $\begin{array}{l}\text { Metode investigasi baru dan belum diterapkan dalam praktik } \\
\text { (percobaan / observasi). }\end{array}$ \\
\hline Evaluation Research & $\begin{array}{l}\text { Metode investigasi diimplementasikan dalam praktik dan } \\
\text { disajikan dalam metode evaluasi. }\end{array}$ \\
\hline Solution Proposal & $\begin{array}{l}\text { Solusi untuk masalah diajukan, usulan solusi ini bisa berupa } \\
\text { pendekatan baru atau berlaku dan pendekatan yang ada. }\end{array}$ \\
\hline Philosophical Paper & $\begin{array}{l}\text { Penelitian ini memperkenalkan perspektif baru tentang sesuatu } \\
\text { yang ada dengan menggunakan taksonomi atau kerangka } \\
\text { konseptual. }\end{array}$ \\
\hline Methods & \multicolumn{1}{c}{ Penjelasan } \\
\hline Metode Kualitatif & $\begin{array}{l}\text { Metode Kualitatif disajikan Rapid Assessment Process, data } \\
\text { sekunder, etnografis, Focus Group Discussions, In-Depth } \\
\text { Interviews, buku harian, dan analisis bahasa. }\end{array}$ \\
\hline Metode Kuantitatif & $\begin{array}{l}\text { Metode Kuantitatif disajikan rancangan sampel, hipotesis dan } \\
\text { pengujiannya, yang semuanya berupa perumusan statistik. }\end{array}$ \\
\hline Mix Methods & $\begin{array}{l}\text { Metode yang memadukan pendekatan kualitatif dan kuantitatif } \\
\text { dalam hal metodologi (seperti dalam tahap pengumpulan data), } \\
\text { dan kajian model campuran memadukan dua pendekatan dalam } \\
\text { semua tahapan proses penelitian. }\end{array}$ \\
\hline
\end{tabular}
Sumber: Olahan Peneliti (2019); Petersen et al (2008).

Hasil pemetaan berdasarkan utama "Transformational Leadership" pertanyaan penelitian untuk dan "Small and Medium Enterprise" yaitu menggambarkan keragaman, tren dan 34 artikel. Berdasarkan hasil pemetaan penyebaran penelitian mengenai dari 34 artikel mengenai Tranformational kepemimpinan transformasional pada Leader dikelompokan dengan UKM yang saat ini.

Setelah melakukan analisis mendalam pada artikel yang ada berdasarkan kriteria yang telah dijelaskan pada Gambar 1 didapatkan hasil akhir jurnal yang bisa dipetakan dengan String menggunakan aplikasi Microsoft Excel 2016 dengan kategori selanjutnya methods, paper type, dan perkembangan penelitian dipenjuru dunia yang dipublikasi oleh Scopus \& Emerald Insight.

\section{Gambar 2. Persentase Penelitian Kepemimpinan Transformasional pada Key String Transformational Leadership}

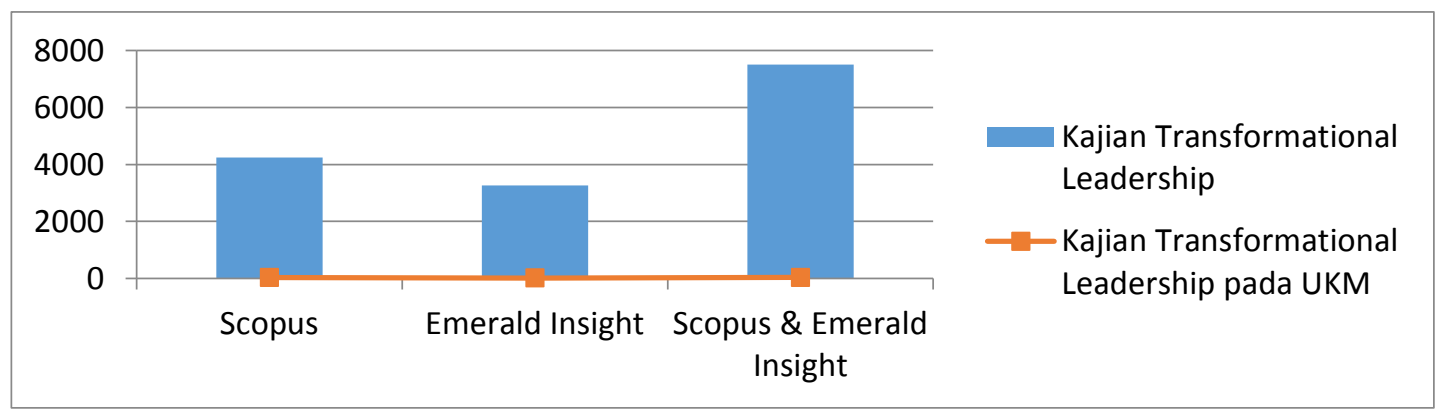

Sumber: Data Olahan Peneliti, 2019 


\section{Hasil dan Pembahasan}

Research Question 1 (RQ1)

Hasil pemetaan dari Gambar 2 total 4273 artikel dengan string "Transformational Leadership" dan "SME" pada Database Journal Electronic International Scopus hanya 0,1\% yang melakukan penelitian mengenai kepemimpinan transformasional pada UKM, sedangkan dari total 3275 artikel dengan String yang sama pada Database Journal Electronic International Emerald Insight hanya $0,37 \%$ yang melakukan penelitian mengenai kepemimpinan transformasional pada UKM.

Hasil dari gabungan pemetaan pada Database Journal Electronic International Scopus \& Emerald Insight dengan jumlah artikel keseluruhan 7548 artikel, hanya $0,50 \%$ atau kurang dari $1 \%$ yang melakukan penelitian mengenai kepemimpinan transformasional pada UKM. Artinya penelitian mengenai kepemimpinan transformasional masih memiliki banyak peluang untuk mengisi kesenjangan (gaps) keilmuan dan peluang publikasi dari kedua jurnal tersebut. Diharapkan hal ini mampu menarik peneliti lain untuk melakukan penelitian mengenai kepemimpinan transformasional pada UKM secara lebih luas dan beragam. Dengan begitu akan tercipta beragam pandangan dan temuantemuan yang baru serta mampu menambah khazanah keilmuan mengenai kepemimpinan transformasional pada UKM. Hal ini sesuai dengan pendapat Barbara Kitchenham. (2004; 2007; 2009; 2011; 2013), bahwa (Systematic Mapping) bertujuan untuk mengidentifikasi kesenjangan dalam penelitian saat ini dan memberikan saran untuk penyelidikan di masa depan, dan juga untuk memberikan latar belakang untuk memposisikan kegiatan penelitian baru.

\section{Gambar 3. Distribusi Jenis Paper}

\section{Distribusi Paper Type}

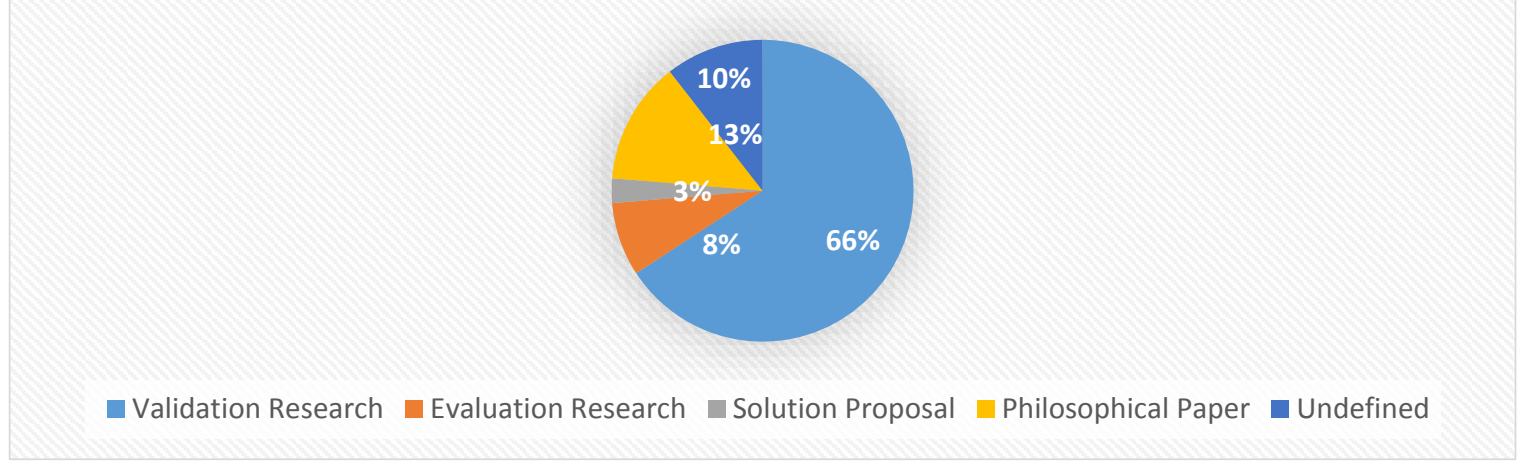

Sumber: Data Olahan Peneliti, 2019

Research Question 2 (RQ2)

Gambar 3 menggambarkan distribusi tipe artikel (paper type) berdasarkan kategori pengklasifikasian menurut Wieringa et al. (2005). Berdasarkan hasil pemetaan secara sistematis (Systematic Mapping Study), tipe artikel yang paling sering digunakan adalah penelitian validasi (validation research) dengan total sebanyak 25 (73\%) dari total artikel penelitian kepemimpinan transformasional pada UKM. Kemudian, tipe artikel yang paling sedikit adalah 
proposal solusi (solution proposal) sebanyak 1 (3\%) dari total artikel penelitian kepemimpinan transformasional pada UKM. Sedangkan yang tidak dapat dikategorikan sebanyak 4 $(10 \%)$ artikel dikarenakan artikel tidak dapat diakses.
Pendekatan metode penelitian yang digunakan pada pemetaan sistematis ini adalah pendekatan kuantitatif, kualitatif, dan mixed-method. Akumulasi total temuan dari 34 jurnal bereputasi Scopus digambarkan pada Gambar 5.

\section{Gambar 4. Distribusi Metode Penelitian}

\section{Distribusi Metode Penelitian}

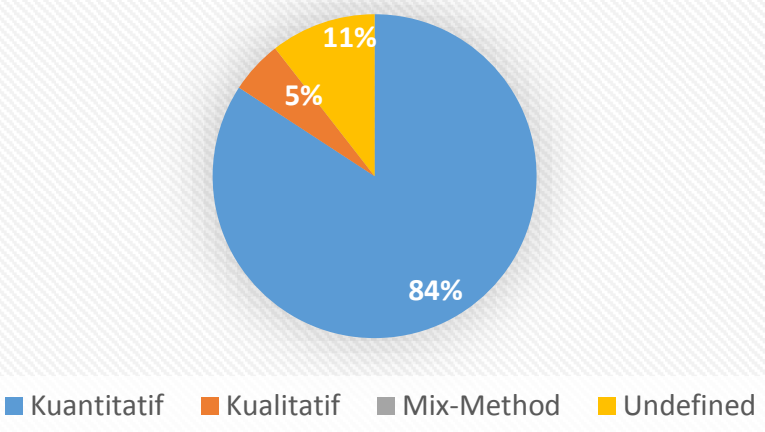

Sumber: Data Olahan Peneliti, 2019

Total artikel pada Gambar 4 tersebut yang melakukan penelitian menggunakan pendekatan kuantitatif ada sebanyak 32 artikel (84\%) penelitian. Selanjutnya diikuti dengan artikel yang menggunakan metode kualitatif sebanyak 2 artikel $(5 \%)$ penelitian dan $11 \%$ artikel undefined dikarenakan artikel tidak dapat diakses sepenuhnya. Dan tidak terdapat penelitian dengan mixed-methods, peneliti berpandangan hal ini dikarenakan kompleksitas metode penelitian mixmethods dalam penelitian kepemimpinan transformasional pada Usaha Kecil Menengah sulit dilakukan.

\section{Gambar 5. Distribusi Berdasarkan Negara}

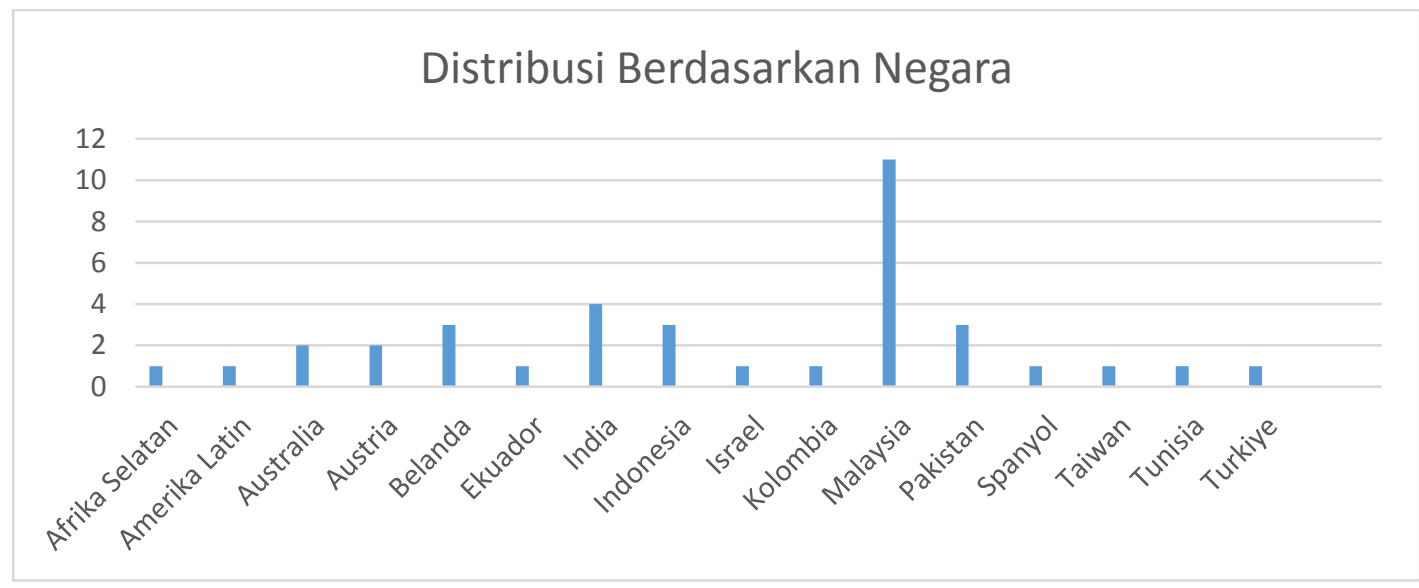

Sumber: Data Olahan Peneliti, 2019 
Research Question 3 (RQ3)

Berdasarkan hasil pemetaan ditemui bahwa negara terbanyak menghasilkan penelitian tentang kepemimpinan transformasional pada UKM adalah Malaysia dengan total 11 publikasi, diikuti India sebanyak 4 publikasi. Pada urutan ketiga terbanyak adalah Indonesia dan Pakistan sebanyak 3 publikasi. Dari hasil ini bisa kita lihat bahwa penelitian mengenai kepemimpinan transformasional pada UKM merupakan penelitian yang menarik terutama bagi kelompok negara-negara berkembang. Dengan semakin banyak penelitian mengenai kepemimpinan transformasional pada UKM diharapkan mampu memberikan solusi \& dampak positif bagi pengusaha kecil \& menengah dalam menjalankan bisnisnya menjadi lebih baik lagi.

\section{Gambar 6. Perkembangan Publikasi dari 10 Tahun Terakhir}

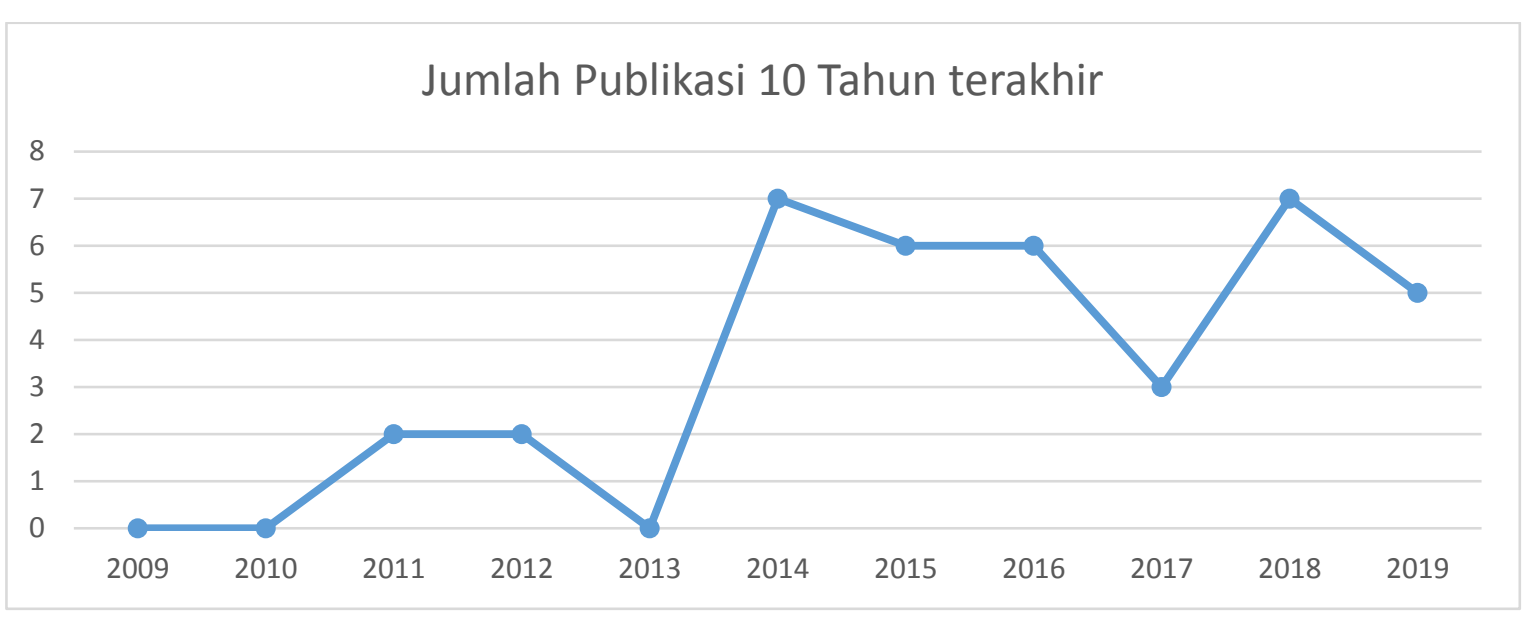

Sumber: Data Olahan Peneliti, 2019

Gambaran tren penelitian pada Gambar 6 tentang kepemimpinan transformasional pada 10 tahun terakhir paling banyak pada tahun 2014 \& 2018 sebanyak 7. Sedangkan pada tahun 2009 \& 2010 tidak terdapat jurnal yang sesuai kriteria pemetaan. Hasilnya menunjukkan adanya peningkatan penelitian mengenai kepemimpinan transformasional pada UKM dari 10 tahun terakhir. Gambaran ini menjelaskan bahwa penelitian kepemimpinan transformasional pada UKM menarik untuk diteliti. Meski ada fluktuasi pada tahun 2013, 2017, dan 2019, namun secara keseluruhan grafik penelitian cenderung naik.

\section{Kesimpulan}

Dalam rangka meningkatkan daya saing dan juga kinerja yang baik di sektor
Usaha Kecil Menengah (UKM), perlu adanya penerapan konsep kepemimpinan transformasional

(Transformational Leadership). Kepemimpinan transfomasional mampu memberikan pengaruh positif pada aktivitas usaha kecil menengah yang bergerak bersama-sama agar mampu bertahan dan bersaing dalam persaingan usaha. Hal ini penting agar mampu memberikan pengetahuan pada penggerak Usaha Kecil Menengah dalam menjalankan usahanya. Peran akademisi, praktisi, dan lembaga riset, serta pemerintah untuk menghasilkan kajiankajian terkait kepemimpinan tranformasional merupakan suatu usaha agar mampu memberikan pengembangan konsep, gagasan dan ide tentang kepemimpinan transformasional pada UKM. 
Penelitian ini memetakan literatur kepemimpinan transformasional pada UKM yang ada pada database ilmiah Scopus \& Emerald Insight. Motivasi utama dari studi yang dipetakan adalah untuk memberikan gambaran umum literatur yang ada tentang kepemimpinan transformasional pada UKM sebagai solusi untuk memenangkan persaingan usaha.

Peneliti menerapkan metode Systematic Mapping Study (Petersen et al., 2008; (Banaeianjahromi., N \& Smolander., 2016). Dari 38 artikel penelitian yang telah di petakan secara sistematik, kami menyimpulkan bahwa:

1) Hasil dari gabungan pemetaan pada Database Journal Electronic International Scopus \& Emerald Insight dengan jumlah artikel keseluruhan 7548 artikel, hanya $0,50 \%$ atau kurang dari $1 \%$ yang melakukan penelitian mengenai kepemimpinan transformasional pada UKM. Artinya masih banyak peluang untuk mengisi kekosongan atau kesenjangan penelitian mengenai kepemimpinan transformasional pada UKM untuk diteliti.

2) Tipe artikel yang paling sering digunakan adalah penelitian validasi (validation research) dengan total sebanyak $25(73 \%)$ dari total artikel penelitian kepemimpinan transformasional pada UKM. Artinya masih banyak tipe penelitian yang belum banyak digunakan dan dapat menjadi peluang penelitian bagi peneliti lain untuk menambah khazanah penelitian dengan tipe penelitian yang beragam.

3) Negara terbanyak yang menghasilkan penelitian tentang kepemimpinan transformasional pada UKM adalah Malaysia dengan total 11 publikasi. Dari hasil yang didapat, penelitian kepemimpinan transformasional pada UKM ini banyak dilakukan pada negaranegara berkembang. Artinya penelitian mengenai kepemimpinan transformasional pada UKM banyak berada di negara-negara berkembang.

Metode penelitian yang diadopsi SMS adalah metode penelitian praktis untuk mengenali topik yang tepat untuk diteliti, serta area mana yang diperlukan untuk lebih banyak penelitian. Hasil penelitian ini memberikan panduan untuk membantu peneliti dalam merencanakan penelitian di masa yang akan datang melalui penemuan kesenjangan penelitian (gaps). Hal ini sesuai dengan pendapat Barbara Kitchenham, (2014; 2007; 2009; 2011; 2013), bahwa Systematic Mapping Study bertujuan untuk mengidentifikasi kesenjangan dalam penelitian saat ini dan memberikan saran untuk penyelidikan di masa depan, dan juga untuk memberikan latar belakang untuk mempromosikan kegiatan penelitian baru.

\section{Daftar Pustaka}

Banaeianjahromi, N., \& Smolander, K. (2016). What Do We Know about The Role of Enterprise Architecture in Enterprise Integration? A Systematic Mapping Study. Journal of Enterprise Information Management, 29(1), 140-164. doi: https://doi.org/10.1108/JEIM-122014-0114.

Barbosa, O., \& Alves, C. (2011). A Systematic Mapping Study on Software Ecosystems. CEUR Workshop Proceedings, 746, 15-26.

Hasibuan, M. S. P. (2011). Manajemen Sumber Daya Manusia. Jakarta: 
Bumi Aksara.

Hermawati, A., Suhermin., \& Puji, R. (2019). The Transglobal Leadership-Based Strategy of MSMEs Performance Optimization of Malang Raya and The Implementation of Quality of Work Life. Research Journal of Textile and Apparel, 23(1), 38-57. doi: https://doi.org/10.1108/rjta-052018-0038.

Kitchenham, B. (2004). Procedures for Performing Systematic Reviews. Keele, UK, Keele University, 33(2004), 1-26.

Kitchenham, B., \& Charters, S. (2007). Guidelines for Performing Systematic Literature Reviews in Software Engineering (Version 2.3)EBSE Technical Report. Keele University and University of Durham.

Kitchenham, B., Brereton, O. P., Budgen, D., Turner, M., Bailey, J., \& Linkman, S. (2009). Systematic Literature Reviews in Software Engineering-A Systematic Literature Review. Information And Software Technology, 51(1), 7-15.

Kitchenham, B., \& Brereton, P. (2013). A Systematic Review of Systematic Review Process Research in Software Engineering. Information and Software Technology, 55(12), 2049-2075.

Lensufiie, Tikno. (2010). Leadership untuk Profesional dan Mahasiswa. Jakarta: Erlangga.
Petersen, K. F. (2008). Systematic Mapping Studies in Software Engineering. 12th International Conference on Evaluation and Assessment in software engineering, p.1. 8, 68-77.

Small Medium Enterprise. (n.d) in U.S Small Business Administration (SBA). Diakses dari https://www.sba.gov/

Undang-Undang Negara Republik Indonesia No. 20 Tahun 2008.

Rivai, V., Bachtiar., \& Amar, B. R. (2013). Pemimpin \& Kepemimpinan dalam Organisasi. Jakarta: PT Raja Grafindo Persada.

Warrilow, S. (2012). Transformational Leadership Theory - The 4 Key Components in Leading Change \& Managing Change. Harvard Business Review, 2(3), 101-104. Diakses dari http://EzineArticles.com/?expert=St ephen_Warrilow

Wieringa, R., Maiden, N., Mead, N., \& Rolland, C. (2006). Requirements Engineering Paper Classification and Evaluation Criteria: A Proposal And A Discussion. Requirements Engineering, 11(1), 102-107. doi: https://doi.org/10.1007/s00766005-0021-6

Yukl, G. (2010). Kepemimpinan dalam Organisasi. Edisi Kelima. Jakarta: PT. Indeks. 